\title{
POLÍTICAS PÚBLICAS PARA HABITAÇÃO POPULAR NO BRASIL: CIÊNCIA OU ARDIL?
}

\section{Public Policies for Popular Housing in Brazil: science or trickery?}

\author{
Eduardo Meireles \\ Universidade do Estado de Minas Gerais - UEMG. \\ Camila Parachini F. Borin \\ Universidade do Estado de Minas Gerais - UEMG.
}

\section{Informações do artigo}

Recebido em 24/08/2020

Aceito em 14/12/2020

doi>: https://doi.org/10.25247/2447-861X.2020.n251.p675-689

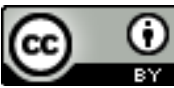

Esta obra está licenciada com uma Licença Creative Commons Atribuição 4.0 Internacional.

\section{Como ser citado (modelo ABNT)}

MEIRELES, Eduardo; BORIN, Camila Parachini F. Políticas Públicas para Habitação Popular no Brasil: ciência ou ardil?. Cadernos do CEAS: Revista Crítica de

Humanidades. Salvador/Recife, v. 45, n. 251, p. 675689, maio/ago. 2020. DOI: https://doi.org/10.25247/2447861X.2020.n251.p675-689

\begin{abstract}
Resumo
A adversidade do déficit habitacional é ainda uma questão pulsante no Brasil. Apesar dos esforços da administração pública, verificados nas últimas décadas, para a produção de políticas públicas atreladas a programas sociais de moradia (em especial o Programa Minha Casa Minha Vida), as condições das Habitações de Interesse Social (HIS) parecem ainda estar distantes da real necessidade das famílias beneficiadas. Dentre outras mazelas, é sabido que existem números expressivos de evasão de moradores neste tipo de conjunto habitacional, enfatizando a sua falta de efetividade na ânsia de suprir a necessidade de moradia ou de promover acesso ao espaço urbano. Sendo assim, este artigo objetiva avaliar as condições em que são construídas as HIS e avaliar se elas atendem às demandas da população, o que seria crucial para avaliar a funcionalidade e promover o aprimoramento destas iniciativas. A partir disso realizou-se uma pesquisa exploratória de publicações com os seguintes termos: moradia, habitação popular, habitação de interesse social, e evasão de conjunto habitacional; e foram selecionados estudos que abrangessem os temas de qualidade das habitações, planejamento urbano, deslocamento ambiental, disponibilidade de infraestrutura de serviços urbanos e conjuntura socioeconômica da população beneficiada. As diferentes necessidades inerentes ao indivíduo, enquanto cidadãos, trabalhadores e usuários do espaço urbano por direito, precisam ser abrangidas na execução dos programas de moradia, e, por este motivo, foram pontos chave destacados neste trabalho para que sejam considerados na construção de políticas públicas habitacionais, em busca de moradias mais satisfatórias, iniciativas mais sustentáveis e de um espaço urbano mais igualitário.
\end{abstract}

Palavras-Chave: Habitação Social. Moradia. Habitação Popular. Déficit Habitacional. Planejamento Urbano.

\section{Abstract}

The adversity of the housing deficit is still a pulsating issue in Brazil. Despite public administration efforts in recent decades to produce public policies linked to social housing programs (in particular the Minha Casa Minha Vida Program), the conditions of Social Interest Housing (HIS) still seem to be far from the real need benefited families. Among other problems, it is known that there are significant numbers of evasion of residents in this type of housing complex, emphasizing its lack of effectiveness in the desire to meet the need for housing or to promote access to urban space. Therefore, this article aims to assess the conditions under which HIS are built and to assess whether they meet the demands of the population, which would be crucial to assess functionality and promote the improvement of these initiatives. From that, an exploratory search of publications was carried out with the following terms: housing, low-income housing, housing of social interest, and evasion of housing; and studies were selected that covered the themes of housing quality, urban planning, environmental displacement, availability of urban service infrastructure and socioeconomic context of the beneficiary population. The different needs inherent to the individual, as citizens, workers and users of urban space by law, need to be covered in the implementation of housing programs, and for this reason were key points highlighted in this work to be considered in the construction of public housing policies, in search of more satisfactory housing, more sustainable initiatives and a more equal urban space.

Keywords: Social habitation. Home. Popular housing. Housing Deficit. Urban planning. 


\section{Introdução}

O déficit habitacional no Brasil tem sido fator de grande problema social. A Habitação de Interesse Social (HIS) não parece ter sido séria preocupação do poder público brasileiro apesar da crescente demanda por habitação desde o século XIX. Atribui-se a isto um conjunto de fatores, em destaque a inexistência de possibilidade de arcar com as despesas de financiamento dessas moradias em sua totalidade (MARQUES; LEITE; MELLO, 2017).

Desde a década de 1980, principalmente após promulgada a Constituição de 1988, o protagonismo das intervenções em prol de habitações populares tem sido das administrações municipais. Entretanto, talvez pela falta de interseccionalidade de recursos, estas iniciativas setoriais locais tendem a falhar ao tentar suprir os diversos problemas advindos do déficit habitacional. Além das evidentes limitações, quando se trata da capacidade de mobilização de recursos financeiros das administrações municipais, existem dificuldades ocorridas da intenção de transferir a propriedade da casa produzida a famílias com restrições agudas de renda e qualidade de vida (CARNEIRO et al., 2015).

Muitos dos constrangimentos que limitam o desenvolvimento urbano equalitário e sustentável se devem a fatores como: planos e leis disfuncionais; fiscalização e urbanização de apenas parte das cidades, implicando em melhorias e direitos para alguns e não para todos; centenária confusão no registro de terras; cadastros públicos imobiliários incompletos e sem informações rigorosas sobre o uso e a ocupação do solo; flexibilidade com a ocupação ilegal fundiária na prática, mas inflexibilidade formal para a regularização de assentamentos de baixa renda; investimentos públicos regressivos, alimentando a exclusão social e os ganhos imobiliários privados (MARICATO, 2006).

Embora o hábito de avaliar a efetividade das políticas públicas no país seja quase inexistente, é de suma importância que tal trabalho seja feito, pois, assim, pode haver adequação dos projetos às reais necessidades e desejos habitacionais dos usuários. Tem-se, com isso, um bom caminho para avaliar construções já ocupadas assim como edificações futuras. Dessa forma, o tema escolhido para esta pesquisa, justificando seu título, é a Habitação de Interesse Social (HIS) que não supre as necessidades das famílias beneficiadas e a taxa de evasão que dela pode decorrer sendo perpetuado o problema do déficit e da inviabilidade destas iniciativas governamentais. O problema de pesquisa, com isso, é definido a partir do seguinte questionamento: Quais os fatores que contribuem para a inadequação 
das condições das moradias populares e o aumento da taxa de evasão daqueles que receberam o auxílio de políticas públicas municipais de habitação?

\section{Justificativa}

Quando nos dispomos a analisar a questão habitacional no Brasil, e as mazelas que advêm de um déficit de moradia que se estende ao longo de décadas, deparamo-nos com contradições que abundam quando confrontamos discursos, leis, planos e projetos formais e a produção concreta do ambiente construído. A ausência de planejamento urbano inteligente, acompanhado de profunda desigualdade social, predação ambiental e aplicação arbitrária da lei não contraria apenas a sustentabilidade ambiental e a igualdade de acesso aos recursos, mas, até mesmo, algumas das condições gerais necessárias para o processo de reprodução do capital, devido ao alto custo do crescimento urbano decorrente da especulação rentista com terras e imóveis. A manutenção de grande número de propriedades urbanizadas ociosas (ou seja, propriedades que foram objeto de investimento público) à espera de valorização e o mercado privado restrito a uma elite econômica são características arcaicas do processo de urbanização, que acabam por interferir nos sistemas de distribuição de habitação, colaborando para perpetuação de suas falhas (MARICATO, 2006).

É notória a característica arriscada deste tipo de abordagem. Pode-se afirmar que, dentro deste tipo de conceituação, há abertura para críticas doutrinárias de legitimação, por meio de uso em pesquisa, de uma estrutura social perversa e criação de um status quo que propõe indiretamente uma cidadania social de segundo nível para populações pobres. Todavia, para atuar positivamente em determinada estrutura social é necessário, primeiro, evitar camuflá-la, assumindo a produção de índices reais e condizentes com a realidade, que considerem as manifestações locais, específicas e heterogêneas, sendo estas em aceitação da expansão das variáveis hegemônicas do sistema econômico ou contra elas (FUNDAÇÃO JOÃO PINHEIRO, 2016).

Segundo dados apresentados pelo censo de 2010 do IBGE, 84\% da população brasileira está estabelecida nas cidades. Entretanto, a rede urbana brasileira é extremamente desigual. Dados da Fundação João Pinheiro mostram que, em 2015, o déficit habitacional brasileiro ultrapassava a casa dos 6,355 milhões de moradias. Destas, $73 \%$ são famílias que 
têm receita de até três salários mínimos, e aproximadamente $87,7 \%$ das famílias necessitadas estão localizadas em áreas urbanas (FUNDAÇÃO JOÃO PINHEIRO, 2016).

Ao analisar o déficit qualitativo, quase um terço do total dos domicílios urbanos permanentes do país, cerca de 16 milhões de moradias, apresenta algum tipo de inadequação: carecem de, pelo menos, um dos serviços públicos (abastecimento de água, esgotamento sanitário, coleta de lixo ou energia elétrica) ou, ainda problemas de padrão construtivo da moradia. Sobretudo, podemos destacar a região Nordeste, que apresenta o pior desempenho, com 35,3\% do total de domicílios inadequados no Brasil (BRASIL, 2014).

É claro que grande parte da responsabilidade pelo déficit está relacionada à má distribuição do espaço urbano. Embora tenha ocorrido uma melhora da legislação com o Estatuto da Cidade (Lei Federal n. 10.257/2001), e a consequente criação de planos diretores, leis de parcelamento e zoneamento do solo, etc. Instituições como Ministério das Cidades, Secretaria de Habitação, Mobilidade Urbana, que também foram criadas em decorrência do Estatuto da Cidade, que chegaram para um melhoramento da vida nas cidades e das condições urbanas, os conflitos latentes neste espaço e os capitais interessados na produção das cidades, com sua forte influência, acabam por pressionar os frágeis governos municipais a atuar em benefício de seus interesses (MARICATO, 2015).

Apesar da legislação previamente mencionada, os empreendimentos particulares acabaram por ser favorecidos na prática, e não a valorização e adequação do espaço urbano e distribuição do mesmo e de moradia. O Programa Minha Casa Minha Vida (PMCMV), que retomou a ponte entre investida empresarial e política habitacional, é o grande responsável pela inversão de propósito, já que ocasionou a construção de moradias indiscriminadamente e com uso imprudente do espaço urbano (MARICATO, 2015).

Sobretudo, este contexto resulta numa forma de produção das cidades um tanto insustentável: com a indústria imobiliária estando altamente dependente de estímulos e verbas do Estado, trazendo um ciclo perigoso de enriquecimento de poucos interesses, em sua maioria privados, a centralização do capital (SHIMBO, 2016) com a elevação dos preços de moradia, a dependência de financiamentos bancários para o acesso da população a estas residências, e sobretudo, o incontrolável espraiamento urbano, que se torna inviável para que a prefeitura possa atender às demandas de equipamento urbano e gera muitos transtornos na mobilidade urbana (LEITE, 2010). 
Ao propor o exame de efetividade dos sistemas de HIS, almeja-se não só uma crítica à forma como são articuladas algumas políticas públicas, e sim uma vinculação da análise técnica a uma verdadeira contribuição social. Para este trabalho, vamos considerar, além da infraestrutura básica, a satisfatoriedade do abastecimento de educação, transporte coletivo, acesso à saúde, mercados e segurança pública para a população deslocada para as HIS de Passos/MG.

Objetivos

Considerando a utilidade dos conjuntos habitacionais na resolução do problema do déficit habitacional, o objetivo principal deste trabalho se resume em levantar, por meio da estimativa de fatores técnicos, estratégicos, construtivos e socioeconômicos, urbanos e culturais, os motivos da não eficácia das políticas públicas de habitação, especialmente nos conjuntos habitacionais desenvolvidos no Brasil nas últimas décadas.

Nesta busca, é inevitável que não se perpasse também pelas necessidades de manutenção dos empreendimentos, a identificação de patologias funcionais e construtivas, o dimensionamento dos aspectos negativos que costumam acontecer nestes ambientes construídos e, principalmente, o destaque dos pontos que necessitem de atenção ou reformulação nas políticas públicas de habitação, de forma a torná-las cada vez mais efetivas e, assim, diminuir a necessidade de outros investimentos pela falta de efetividade dos já executados.

\section{Procedimentos metodológicos}

Para a realização deste trabalho, realizou-se uma pesquisa exploratória com um levantamento bibliométrico simples, e conseguinte revisão da literatura específica encontrada para dar fundamentação teórica à hipótese de pesquisa, visando, também, proporcionar maior familiaridade com o problema.

A revisão da literatura, ou revisão bibliográfica, pretende demonstrar em que nível se encontra a produção acadêmica a respeito daquele determinado assunto. Ela deve ter uma boa abrangência sobre pesquisas passadas, conduzindo o pesquisador ao ponto necessário para estudos futuros ou o objetivo do próprio trabalho em questão (SANTOS, 2012). 
Assim sendo, foram selecionados os seguintes termos de pesquisa: "moradia", "habitação popular", "habitação de interesse social", e "evasão de conjunto habitacional", e foram realizadas buscas que retornassem com a intersecção de pelo menos dois dos termos escolhidos.

Foram utilizadas as seguintes bases de dados para a realização destas buscas: Portal de Periódicos CAPES, SciELO - Scientific Electronic Library Online, Directory of Open Access Journals, Google Schoolar, além de pesquisas em revistas com áreas específicas para temas de urbanismo e habitação, como a Revista Urbe.

Houve, inicialmente, um retorno de 41 artigos. Em função da quantidade, definiu-se novo critério de seleção com a leitura dos resumos e, assim, os artigos foram avaliados e compatibilizados em relação aos outros eixos da pesquisa, sendo estes: qualidade das habitações, disponibilidade de infraestrutura de serviços urbanos nas proximidades das áreas onde as moradias eram edificadas, a consideração do contexto do planejamento urbano e do deslocamento socioambiental realizado nestes empreendimentos, e a conjuntura socioeconômica da população beneficiada.

Em conseguinte, a pesquisa inicial se tornou um escopo de 16 artigos que foram estudados para a realização do presente estudo.

\section{Desenvolvimento}

Pode-se dizer que as políticas públicas habitacionais no Brasil ganham real expressão após 1964, com A Lei No 4.380, que instituiu o Plano Nacional de Habitação, criando o Banco Nacional de Habitação (BNH) e o Serviço Federal de Habitação e Urbanismo. O chamado Sistema Financeiro de Habitação, a princípio, era financiado pelo Sistema Brasileiro de Poupança e Empréstimo (SBPE) mas, em seguida, passa a ser gerido pelo Fundo de Garantia por Tempo de Serviço (FGTS) (ZAPELINI; LIMA; GUEDES, 2018).

Em diferentes estados, as Companhias de Habitação (COHAB) financiavam e construíam habitações, para, depois, repassar a preço de custo aos consumidores finais (as classes de renda mais baixa). Estes, por sua vez, pagariam o financiamento às COHAB. Mas logo, devido às taxas impraticáveis de reajuste de juros em comparação aos reajustes dos salários, a partir de 1975, as COHAB passaram a financiar habitações para famílias com renda superior a cinco salários perdendo, assim, sua função original. Esta situação se agrava a partir 
da década de 1980, com a redução dos investimentos no setor habitacional, especialmente após a extinção do Banco Nacional de Habitação (BNH), no final de 1986 (ZAPELINI; LIMA; GUEDES, 2018).

De acordo com Bonduki (1998), na década de 90, tentou-se a retomada de alguns financiamentos pelo FGTS e foi criado o Plano de Ação Imediata para Habitação (PAIH), o qual pretendia construir 200.000 novas habitações em seis meses, mas que não conseguiu atingir suas metas. Alguns anos mais tarde, cria-se a Política Nacional de Habitação (1996), porém os programas deste período não atingiram a população de baixa renda, estimando-se crescimento do déficit habitacional em 40,9\% na faixa de renda inferior a 2 salários mínimos, enquanto que, na faixa superior a 5 salários mínimos, o déficit reduziu-se em $26,5 \%$.

Porém, graças ao crescente processo de descentralização e municipalização, impulsionado pela Constituição de 1988 e pela reforma tributária, que ampliou os recursos dos municípios, é conferida maior autonomia aos governos municipais para formulação de políticas específicas, através das quais podem ser identificadas algumas mudanças decorrentes desse processo (BRASIL, 2014).

Em 2001, após 13 anos de debate no Congresso Nacional, é aprovado o Estatuto das Cidades, o que gerou novos instrumentos urbanísticos que permitem a legalização fundiária e efetivam a função social da propriedade. No ano de 2003, passa-se a ver uma focalização na população de baixa renda, oferecendo taxas de juros mais baixas. É criado também o Ministério das Cidades, constituindo-se no primeiro órgão a ser incumbido, essencialmente, da questão habitacional desde o BNH. Nasce também o Projeto Moradia, uma estratégia geral para a solução do problema do déficit habitacional. Moscarelli e Kleiman (2017, p.157) apontam que o Estatuto e o Ministério das Cidades juntos, "representam a primeira experiência brasileira democrática de gestão territorial urbana, enquanto o Ministério representa um esforço institucional intersetorial jamais realizado em território nacional".

Em 2005, com a criação do Conselho Nacional das Cidades, junto do Subsistema de Habitação de Interesse Social, buscou-se criar condições institucionais para que os recursos do FGTS sejam canalizados para a esfera social. Passa a existir, também em 2007, o Programa de Aceleração do Crescimento (PAC), que incluiu investimentos nas áreas de habitação e saneamento, buscando atingir as populações de mais baixa renda, a partir de um direcionamento de aplicações para a urbanização de assentamentos precários. E finalmente, em 2009, procurou-se reduzir o déficit habitacional, por meio da Lei $\mathrm{N}^{0} 11.977 / 2009$, a qual 
criou o Programa Minha Casa, Minha Vida (PMCMV), que perdura até hoje, passando por algumas reformulações e novos recursos a partir de 2011 (ZAPELINI; LIMA; GUEDES, 2018).

$\mathrm{Na}$ busca pela resolução do problema habitacional urbano de forma concreta, obviamente deve ser levado em consideração todo um aparato de serviços públicos e infraestrutura urbana, de forma a garantir habitações realmente efetivas e qualidade de vida aos usuários.

O conceito de serviço público urbano diferencia-se de infraestrutura e equipamentos urbanos, de forma que infraestrutura urbana compreende a rede física propriamente dita (rede de tubulações de abastecimento de água) e o serviço de gestão do abastecimento de água (a operação, a tarifação e a manutenção da rede) representam o serviço público de abastecimento de água. De acordo com Abiko (1995), no caso dos equipamentos urbanos, também se pode fazer a mesma distinção, isto é, no caso da educação, os edifícios representam o equipamento urbano, enquanto a gestão do sistema educacional e o gerenciamento das atividades escolares representam o serviço público de educação.

A instituição, a regulamentação, a execução e o controle dos serviços públicos de interesse coletivo cabem sempre ao Poder Público. O fato de alguns serviços serem delegados a terceiros (iniciativa privada) não desobriga que a Administração Pública tenha função de regulação sobre as atividades a ela subordinadas (ABIKO, 1995). São considerados serviços urbanos: arruamento, alinhamento e nivelamento; água e esgotamento sanitário; coleta de lixo e limpeza de vias públicas; drenagem de águas pluviais; trânsito e tráfego; transporte coletivo; iluminação pública; energia elétrica; serviços telefônicos; distribuição de gás; educação e ensino, saúde e higiene; mercados e feiras; serviços funerários; segurança pública; esporte, lazer, cultura e recreação; defesa civil, entre outros.

Quando analisamos as políticas de HIS e a forma como elas são aplicadas, temos geralmente a seguinte conjuntura: de um lado, as expectativas da população de baixa renda, que anseia ter em sua habitação condições mínimas de salubridade, segurança, legitimidade, durabilidade, conforto ambiental e adequação espacial e, do outro, o Poder Público buscando atender os anseios da população apenas com políticas públicas específicas de assentamento, quase sempre produzindo conjuntos habitacionais novos em regiões distantes dos locais de emprego e carentes de infraestrutura, ocasionando perda de tempo e recursos escassos dispendidos com deslocamentos intraurbanos. Ademais, não existe, na agenda do setor 
público, nenhum tipo de "assistência técnica" ou de estudo de funcionalidade destes conjuntos (FERREIRA; RACHID, 2010).

Um segundo problema se encontra na capacidade efetiva de as famílias contempladas pela política municipal da habitação arcarem com o pagamento do imóvel e o custo de sua manutenção. Quando se transfere a posse da unidade habitacional para a família atendida, supõe-se uma disponibilidade de renda familiar compatibilizada à manutenção da edificação, que vai desde manutenções físicas de habitabilidade da construção, até contas de água, energia, gastos com mobiliário, entre outros (CARNEIRO et al., 2015).

Assim sendo, famílias com capacidade de buscar soluções próprias para suas necessidades de moradia acabam por adquirir a propriedade destes imóveis produzidos pela política pública, com o concomitante deslocamento dos moradores originais, distanciando as políticas de habitação dos seus objetivos originais de favorecer o acesso à moradia às famílias dos estratos inferiores de renda, sobretudo a famílias com reduzida capacidade de mobilizar recursos financeiros - com destaque para aquelas chefiadas por mulheres com dificuldades de ingressar no mercado de trabalho (CARNEIRO et al., 2015).

Ou seja, existem diversos fatores determinantes quando se trata da questão habitacional e da relocação destas pessoas, que não podem ser analisados de forma linear, o que reafirma as limitações que acometem políticas públicas ao lidar com a questão habitacional dos segmentos mais vulneráveis da população mais carente. Quando se considera a questão antropológica, compreende-se, ainda, que existe um constrangimento por parte da família premiada com a casa própria, criando-se uma obrigação de se esforçar por merecê-la, buscando formas de incrementar seus rendimentos monetários, numa espécie de conversão do direito à moradia na obrigação ao trabalho remunerado, de modo a conseguir arcar com o ônus de sua nova condição. Entretanto, de forma geral, os beneficiados com a moradia cedida pela Prefeitura não parecem ter recursos para cumprir com este contrato, visto que este envolve considerações ligadas à escolarização formal e às fontes de remuneração, que, quando equacionados, evidenciam as difíceis condições de vida das famílias moradoras nos conjuntos habitacionais construídos pela política municipal da habitação (CARNEIRO et al., 2015).

Desta forma, pode-se inferir, de maneira ousada, que a relação benefício-custo pode não ser compensatória para o atendido. E, mais além, poder-se-ia também apontar 
problemas semelhantes nas novas iniciativas federais para habitação, representadas, hoje, principalmente pelo programa "Minha Casa, Minha Vida" (CARNEIRO et al., 2015).

Sobretudo, há que se considerar, também, que as cidades geralmente apresentam uma clara divisão entre as áreas ocupadas pelos grupos mais ricos, e os espaços confinados onde estão os grupos mais pobres. Esta divisão não pressupõe que os locais dessas moradias estejam distantes uns dos outros, a separação entre essas moradias pode ser apenas social. Entretanto, o processo de segregação socioespacial inclui a desigualdade de acesso aos recursos existentes na cidade, como os recursos econômicos, culturais, ambientais e outros. E esta segregação influencia drasticamente no processo de expansão e crescimento urbano (COELHO, 2012).

Ainda pertencente a esta questão, deve-se considerar que as famílias beneficiadas pelos programas de moradias muitas vezes não podem, realmente, opinar sobre questões importantes de sua nova habitação. São reassentados em lugares que, por vezes, são indesejados, ou que não atendem total ou parcialmente suas demandas. De acordo com Oliveira, Lopes e Sousa (2018, p. 328) "a participação pública apresenta como benefício o acolhimento dos interesses coletivos, o que possibilita o ajustamento da atuação da administração pública às efetivas necessidades da população".

Nesse mesmo sentido, políticas públicas continuam a focalizar os mais pobres dentre os pobres, o que torna a pobreza um referencial distante da discussão sobre cidadania e universalidade das políticas públicas. De acordo com Koga (2011, apud COELHO, 2012) o tratamento reducionista e homogêneo de populações distintas leva a análise do aspecto territorial apenas como uma referência de localização da população e não como espaço de produção e reprodução das relações sociais.

Conforme o que foi previamente exposto, a criação de novas habilitações pouco ajuda se não for pensada em estreita articulação com as necessidades dos moradores que virão a habitá-las. O acesso à casa própria viabilizada pela política municipal da habitação tende a pressionar ainda mais a precária base de renda das famílias moradoras dos conjuntos habitacionais, as quais encontram severas coações quanto a prover a própria subsistência (CARNEIRO et al., 2015).

Enquadram-se aqui as exigências ou demandas do mercado formal de trabalho, e diversas limitações referentes à localização: o acesso ao transporte público e mobilidade, 
incluso tempo de deslocamento ao local de trabalho, disponibilidade de vagas no sistema educacional, acesso à saúde pública, entre outros.

Uma política coerente de habitação para as classes mais desfavorecidas deve ter como diretriz assegurar aos atendidos condições para proverem a própria subsistência, o que passa pela qualificação para o trabalho e devido acesso aos serviços públicos básicos. Sem políticas mais robustas e consistentes de inclusão socioeconômica, a dependência do estado para provisão de serviços básicos e, sobretudo, as incertezas da renda familiar dificultam muito a assunção do ônus advindo da propriedade da "casa própria". O constrangimento de ameaças financeiras de curto prazo muitas vezes inviabiliza qualquer perspectiva de progresso a longo prazo, conjecturando os contemplados pela intervenção setorial do governo em uma parcela que garantiu o direito constitucional à moradia sem, entretanto, ter conseguido o direito à adequação de sua condição de vida, o que, muitas vezes, transcende os limites das ações de até programas como o Pós Morar ${ }^{1}$.

Ao pontuarmos as questões de evasão e de efetividade dos empreendimentos de HIS, abrimos caminho para duas possíveis análises de sustentabilidade: a sustentabilidade ambiental, que seria a sustentabilidade propriamente dita, e ainda, a sustentabilidade de investimento neste tipo de política, considerando que elas não têm sido, de fato, satisfatórias.

Em se tratando de sustentabilidade ambiental, é certo afirmar que, quando não há investimentos em infraestrutura urbana de forma concomitante ao crescimento do espaço urbano, a demanda logo se tornara maior que a oferta de serviços urbanos, caracterizando um desequilíbrio perigoso. A falta de manutenção dos equipamentos urbanos vem, por sua vez, exacerbar o déficit na oferta de serviços, o que inevitavelmente ocasionará uma segregação social e territorial entre as populações abastecidas e não abastecidas por estes serviços.

Esta "queda de produtividade política dos investimentos urbanos" causa um dano no processo de construção urbana, acentuando graus de conflito e incertezas, e gerando um

1 O programa Pós-Morar teve como objetivo desenvolver ações sociais que melhorem a qualidade de vida e os padrões de convivência dos mutuários nos conjuntos habitacionais, bem como prevenir a inadimplência. Suas ações envolviam orientação educativa, geração de renda, cuidados pessoais e com a casa, além de conscientização de direitos e obrigações dos mutuários. 
processo de instabilidade das políticas urbanas, tanto na forma da incapacidade de gerir a administração dos recursos públicos, quanto na falha de democratizar o acesso de todos aos serviços urbanos. A insustentabilidade se estabelece aqui, na insuficiente adesão à racionalidade econômica, no desperdício dos recursos ou, ainda, na ausência de priorizar a distribuição do acesso a tais serviços. O impacto material das políticas será, consequentemente, contestado, seja pelo ângulo do desperdício de meios, seja pelo da concentração socioterritorial dos benefícios (ACSERALD, 1999).

Em se tratando da sustentabilidade das políticas públicas habitacionais, os baixos índices de acesso às oportunidades e serviços urbanos, são condição inviabilizadora para a sustentabilidade da política habitacional desenvolvida pelos municípios, resultando em evasão das famílias beneficiadas dos complexos, voltando a somar no déficit habitacional e perpetuando o problema, apesar dos investimentos.

Uma técnica que, provavelmente, se mostraria eficaz para a quebra deste ciclo, seria a "realimentação" dos projetos de empreendimentos similares. A realimentação é o processo de identificação das falhas e possíveis melhorias, e sua adaptação em diretrizes a serem seguidas em espaços futuros, garantindo, desta forma, a melhoria e otimização constante de novos projetos e do planejamento urbano.

Esta realimentação pode ser feita, inclusive, utilizando-se técnicas de Avaliação PósOcupacional (APO), que, segundo Ornstein (1992), é um dos mecanismos eficientes de realimentação de projetos semelhantes e de controle de qualidade global do ambiente construído. É um dos mecanismos mais satisfatórios e ferramenta eficaz na garantia da qualidade geral do ambiente construído, sendo que esta pode ser aqui definida como o potencial de um determinado produto de satisfazer seus usuários.

\section{Considerações finais}

O equacionamento do problema da habitação no Brasil se mantém como um desafio ao poder público, que não consegue suprir satisfatoriamente crescentes carências habitacionais das famílias mais pobres (BRASIL, 2014).

Num contexto de desigualdade social, e um contexto político convenientemente determinista, a habitação para população de baixa renda foi, muitas vezes, entendida, de 
fato, como habitação pobre, que poderia ser produzida e distribuída mesmo com baixa qualidade (SIQUEIRA; ARAÚJO, 2014).

Ainda, para a construção de muitas destas moradias, o poder público escolhe ou desapropria grandes lotes distantes do centro urbano, que, talvez, não se possa chamar de escolha, devido ao monopólio e influência dos capitais imobiliários que acabam por limitar a gama de possibilidades de território até mesmo para o Estado em alguns contextos. Este cenário acarreta construções de má qualidade, em locais distantes e, muitas vezes, sem os aparatos urbanos necessários à população como escolas, creches, postos policiais e de saúde, e, sobretudo, sem acesso ao transporte e à mobilidade urbana, formando os chamados "clusters" (ROLNICK, 2003) ou guetos, que acabam por estarem localizados completamente à margem do restante da urbe (SIQUEIRA; ARAÚJO, 2014).

Assim sendo, os Programas de Habitação Popular no Brasil carecem de melhorias tanto em seus projetos quanto na qualidade construtiva de suas habitações, que são, além de tudo, realizadas fora da ótica de uma política habitacional e urbana condizente com a realidade econômica dos usuários e das administrações públicas municipais. Esta cascata de problemas de planejamento acaba por gerar um enorme desperdício de recursos ambientais, econômicos e até mesmo uma desgaste da qualidade de vida destas populações, que são deslocadas de suas rotinas, culminando num looping dos índices de déficit habitacional que jamais serão sanados desta maneira.

\section{Referências}

ABIKO, A. K. Serviços públicos urbanos. São Paulo: EPUSP, 1995. (Texto técnico da Escola Politécnica da USP, Departamento de Engenharia de Construção Civil, TT/PCC/10).

ACSERALD, H. Discursos da Sustentabilidade Urbana. Revista Brasileira de Estudos Urbanos e Regionais, publicação semestral da Anpur, n. 1, p.79-90, maio 1999.

ALVES, A. J. A "Revisão da Bibliografia" em Teses e Dissertações: meus tipos inesquecíveis. Cadernos de Pesquisa, São Paulo, n. 81, p. 53-60, 1992.

BONDUKI, Nabil. Origens da Habitação Social no Brasil. Arquitetura moderna, Lei do Inquilinato e difusão da casa própria. São Paulo: Estação Liberdade: FAPESP, 1998.

CARNEIRO, R; SOUZA, J. M.; BRASIL, F. D.; BARBOSA, T. P. Habitação de interesse social: considerações a partir da experiência de Belo Horizonte. Revista Avaliação de Políticas Públicas-AVAL, [S.I.], v. 2, n. 6, p. 7-16, 2015. 
COELHO, J. M. Evolução urbana no Distrito Federal entre 2000 e 2010: aspectos socioeconômicos, morfológicos e ambientais da segregação socioespacial. 2012. $128 \mathrm{f}$. Dissertação (Mestrado em Arquitetura e Urbanismo) - Faculdade de Arquitetura e Urbanismo (FAU), Universidade de São Paulo, São Paulo, 2012.

FERREIRA, M. RACHID, M. Z. Subsídios para a Implantação de um Programa Municipal de Atendimento Técnico à Habitação Social por Auto-Construção Assistida em Passos (MG). Ciência ET Praxis, [S.I.], v. 3, n. 6, p. 75-82, 2010.

FLICK, U. Introdução à pesquisa qualitativa. 3. ed. Porto Alegre: Artmed, 2009.

FUNDAÇÃO JOÃO PINHEIRO. CENTRO DE ESTATÍSTICAS E INFORMAÇÕES. Déficit Habitacional no Brasil 2013 - 2014. Belo Horizonte, 2016. Disponível em: http://www.fjp.mg.gov.br/index.php/docman/cei/informativos-cei-eventuais/634deficithabitacional-06-09-2016/file Acesso em: 01 agosto 2018.

GEOSISTEMAS ENGENHARIA E PLANEJAMENTO. Plano Estadual de Habitação de Interesse Social do Estado do Maranhão - PEHIS-MA. Diagnóstico do setor habitacional. São Luiz: Governo do Estado do Maranhão, 2014.

LEITE, C. Cidades sustentáveis? Desafios e oportunidades. Campinas, n. 118, 2010. Disponivel em: http://comciencia.scielo.br/scielo.php?script=sci_arttext\&pid=S1519-abril 2019.

MARICATO, E. A nova política nacional de habitação. O Valor, São Paulo, p. 1-3,24 nov. 2005 .

MARICATO, E. Para Entender a Crise Urbana. CaderNAU, Rio Grande, n. 8, p. 11-22, 2015.

MAROUES, A. C. D.; LEITE, K. S.; MELLO, M. Habitação de Interesse Social no Município de Anápolis - Goiás: análise da reprodução da segregação residencial. Anais - Seminário de Pesquisa, Pós-Graduação, Ensino e Extensão do CCSEH - IIISEPE, p.1-5, 2017.

MOSCARELLI, F.; KLEIMAN, M. Os desafios do planejamento e gestão urbana integrada no Brasil: análise da experiência do Ministério das Cidades. Revista Brasileira de Gestão Urbana (Brazilian Journal of Urban Management), [s.I.], v. 9, n.2, p. 157-171, maio/ago. 2017.

MOZZATO, A. R., GRZYBOVSKI, D. Análise de Conteúdo como Técnica de Análise de Dados Qualitativos no Campo da Administração: potencial e desafios. RAC, Curitiba, v. 15, n. 4, p. 731-747, jul./ago., 2011.

OLIVEIRA, C. M.; LOPES, D.; SOUSA, I. C. N. Direito à participação nas políticas urbanísticas: avanços após 15 anos de estatuto da cidade. Revista Brasileira de Gestão Urbana (Brazilian Journal of Urban Management), v. 10, n. 2, p. 322-334, maio/ago., 2018.

ORNSTEIN, S. Avaliação Pós-Ocupação do Ambiente Construído. São Paulo, SP: Studio Nobel, Editora da Universidade de São Paulo, 1992.

ROLNIK, R. Política Urbana no Brasil-Esperança em Meio ao Caos? Revista dos Transportes Públicos-ANTP, v. 25, p. 3, 2003. 
SANTOS, V. O Que é e Como Fazer "Revisão Da Literatura" na Pesquisa Teológica. Fides Reformata XVII, Campo Belo, n. 1, p. 89-104, 2012.

SIQUEIRA, T. A.; ARAÚJO, R. de S. (2014). Programas de habitação social no Brasil.

Perspectivas Online: Humanas e Sociais Aplicadas, [S.I.], v.4, n. 10, p. 45-54, 01 jul. 2014. Disponivel em: https://doaj.org/article/d3613697c97747beb485ae6oc44835ec. Acesso em: 02 jan. 2020.

SHIMBO, L. Sobre os Capitais que Produzem Habitação no Brasil. Novos Estudos Cebrap, São Paulo, v. 105, p. 119-133, jul., 2016.

ZAPELINI, M. B.; LIMA, J. G.; GUEDES, M. C. Evolução da Política Habitacional no Brasil (1967-2014): uma análise de equilíbrio pontuado. Revista Interdisciplinar de Gestão Social, v. 6, n. 3, p.153-174, 2018.

\section{Detalhes dos autores}

Eduardo Meireles

Doutor e Mestre em Engenharia Urbana pela Universidade Federal de São Carlos, professor e membro permanente do Mestrado Profissional em Desenvolvimento Regional e Meio Ambiente da Universidade do Estado de Minas Gerais-UEMG, ----.---@uemg.br.

Camila Parachini F. Borin

Mestranda no Programa de Pós-Graduação em Desenvolvimento Regional e Meio Ambiente da Universidade do Estado de Minas Gerais-UEMG, campus de Passos, Minas Gerais, Brasil, ------2105036@discente.vemg.br. 